\title{
Phase II Trial of Gemcitabine, UFT-E, Leucovorin Combination Chemotherapy in Advanced Pancreatic Adenocarcinoma
}

So Young Yoon, M.D. ${ }^{1}$, Kyong Hwa Park, M.D. ${ }^{1}$, Sang Chul Oh, M.D. ${ }^{1}$, Jae Hong Seo, M.D. ${ }^{1}$, Chul Won Choi, M.D. ${ }^{1}$, Byung Soo Kim, M.D. ${ }^{1}$, Jae Seon Kim, M.D. ${ }^{2}$, Chang Duck Kim, M.D. ${ }^{2}$, Sang Won Shin, M.D. ${ }^{1}$, Yeul Hong Kim, M.D. ${ }^{1}$ and Jun Suk Kim, M.D. ${ }^{1}$

${ }^{1}$ Section of Hemato-Oncology, Department of Internal Medicine, College of Medicine, Korea University Hospital, Seoul, Korea, ${ }^{2}$ Section of Gastro-enterology

Purpose: To evaluate the efficacy and toxicity of a Gemcitabine, UFT-E, Leucovorin combination chemotherapy in the treatment of advanced pancreatic adenocarcinoma Patients and Methods: Patients $\leq 70$ years, with no prior chemotherapy and with bidimensionally measurable advanced pancreatic adenocarcinoma, ECOG performance status $\leq 2$, and adequate bone marrow, kidney, and liver function were eligible for this trial. Eligibility criteria for clinical benefit assessment were pain with at least a daily analgesic consumption of two nonsteroidal anti-inflammatory drugs or a Karnofsky performance status between 50 and 70 . Treatment consisted of 1,000 $\mathrm{mg} / \mathrm{m}^{2}$ of Gemcitabine on days 1,8 and 15 , repeated every 4 weeks, with UFT-E administered orally $500 \mathrm{mg} \sim 700 \mathrm{mg}$ by body surface area (BSA). Leucovorin was administered $45 \mathrm{mg} /$ day orally. Dosages of UFT-E and Leucovorin were divided and administered three times per day from day 1 to day 21. After 7 days of rest, UFT-E and Leucovorin were administered repeatedly.

Results: Twenty-three patients were enrolled between April 1999 to April 2000. Eighty two cycles (median, four

\section{서 론}

췌장암은 진단 6 개월 이내에 사망률이 $65 \%$ 에 달하고 1 년 이내에 거의 $90 \%$ 이상이 사망하는 가장 치명적인 암 중의 하나이다. 더구나 진단 당시에 $80 \%$ 이상의 환자들이 이미 국소적으로 진행되어 있어서 수술이 불가능하거나 다른 장 기로 전이되어 있는 상태로 이런 환자들에 있어서 진단 후 생존 후 중앙값은 4 개월 이내이다 $(1,2)$. 그러나 진행성 췌장

Correspondence: Jun Suk Kim, Korea University Guro Hospital, Gurodong-gil 97, Guro-gu, Seoul 152-703, Korea. (Tel) 82-2-

818-6651, (Fax) 82-2-862-4453, (E-mail) kjs6651@kumc.or.kr Received December 10, 2001, Accepted March 20, 2002 This work was supported by the Brain Korea 21 Project in 2001. cycles) were delivered to all patients. The objective response rate was $15.8 \%$ in 19 assessable patients and $13.0 \%$ in the intent-to-treat population. Twelve patients $(57.9 \%)$ displayed stable disease. Grade 3 or 4 neutropenia occurred in $30.4 \%$ of patients, nausea/vomiting in $8.3 \%$, diarrhea in $4.3 \%$, and mucositis in $4.3 \%$. The median time to progression was 8 months. The median survival was 8 months in the assessable population and 6 months in the intent-to-treat population Clinical benefit was achieved in $11(57.9 \%)$ of 19 assessable patients.

Conclusion: Gemcitabine, UFT-E, Leucovorin combination chemotherapy is a well-tolerated and safe regimen in cases of advanced pancreatic adenocarcinoma. Although the response rate is low, it shows a survival benefit and clinical benefit and deserves further evaluation in a phase III trial. (Cancer Research and Treatment 2002;34:111116)

Key Words: Pancreas neoplasm, Combination chemotherapy, Gemcitabine, UFT-E, Leucovorin

암에서 항암요법의 사용은 지난 20 년간 연구를 해왔으나 뚜렷한 효과를 보이지 못하고 있다. 비록 많은 항암제와 복 합항암요법 등이 제 2상 연구 및 3상 연구에서 시행되었으 나 계속 실망적인 결과를 보였고 반응률은 0 20\%에 불과 하였고 생존의 중앙값은 5 6개월 미만이었다. 또한 여러 가지 항암제의 복합항암요법도 항암제 단독치료에 비해 우 월하지 못했다(3 6). Gemcitabine은 반응률은 6 15\%로 낮 지만(7 10) 독성이 적고 약 $1 / 4$ 의 환자에서 통증 완화 및 전신 수행능력의 상승 등 임상적 이익이 있었으며, 3 상 임 상연구에서 5-FU보다 반응률이 좋고 생존율의 향상 및 임 상적인 증상의 완화에 있어서도 우월하였다(11).

췌장암에서 가장 흔하게 사용되는 항암제는 $5-\mathrm{FU}$ 이지만 반응률은 $20 \%$ 이상을 넘지 못하고 생존률의 향상이나 질병 과 관련된 증상의 완화에는 크게 도움이 되지 않았고 $5-\mathrm{FU}$ 
를 포함한 복합항암 요법도 5-FU 단독에 비해 독성만 증가 시켰고 더 나은 결과를 보이지 않았다(4 6). 그러나 5-FU 를 지속 정주하는 것은 대장암에서 일시 정주 하는 것보다 더 나은 효과를 보이면서 독성은 적었고(12) 진행성 췌장암 에서 5-FU의 지속 정주와 다른 항암제와의 복합 항암 요법 에서 반응률 $15 \sim 20 \%$ 의 비교적 좋은 결과를 보였다(13 17). 그러나 5-FU의 지속 정주는 중심 정맥관의 삽입이 장 기간 필요하여 이로 인한 합병증이 발생하고 삶의 질을 저 하시키는 단점이 있다. 그에 비해 UFT-E의 경구 투여는 5-FU의 지속 정주와 유사한 효과를 가지면서 먹는 약으로 외 래 환자에서 쉽게 사용할 수 있고 독성이 나타났을 경우에 끊 을 수 있는 장점이 있다. 본 교실에서는 경구 UFT와 Leucovorin 복합항암요법으로 진행된 위암에서 반응률 $27 \%$ 의 결과를 보고한 바 있고(18) 진행성 위암 환자에서 Epirubicin, Cisplatin, UFT, Leucovorin 복합항암요법에서 반응률 $54 \%$, 생존기간 의 중앙값 12 개월로 좋은 결과를 보고한 바 있다(19). 5-FU 와 Gemcitabine의 복합항암요법은 실험 모델에서 서로 상승 작용이 있고 다른 독성을 보였다(20).

이에 본 교실에서는 진행성 췌장암에서 Gemcitabine, UFT-E, Leucovorin 복합 항암요법의 효과와 독성을 평가하기 위한 제2상 임상연구를 시행하였다. 복합항암요법의 효과는 임 상적 이익 및 반응률, 생존 기간으로 평가하였다.

\section{대상 및 방법}

\section{1) 환자}

1999년 3월부터 2001년 3월까지 고려대학교 구로 부속병 원과 안암 부속병원에서 조직학적으로 진단된 진행성 췌장 암, 즉 국소적으로 진행되어 수술이 불가능하거나 전이성 암을 대상으로 하였다. 대상 환자 기준은 ECOG 전신 수행 능력이 2 이하이거나 Karnofsky 전신 수행능력이 50 이상이 고 나이는 70세 이하인 환자를 대상으로 하였고 최소한 한 개 이상의 계측 가능한 병변이 있어야 하고 이전에 방사선 치료나 항암 치료를 받은 환자는 제외시켰다. 절대 호중구 수 $\geq 1,500 / \mathrm{mm}^{3}$ 혈소판 수 $\geq 100,000 / \mathrm{mm}^{3}$, 혈색소 $\geq 10 \mathrm{~g} / \mathrm{dL}$, 혈청 크레아티닌 $\leq 1.5 \mathrm{mg} / \mathrm{dL}$ 이고 혈청 총 빌리루빈 $\leq 2$ $\mathrm{mg} / \mathrm{dL}$, 혈청 트랜스아미나아제 $\leq$ 정상의 3 배로 항암치료에 적합한 간기능 및 골수 기능과 신장 기능을 가진 환자를 대상으로 하였다. 그러나 종양에 의한 담도 폐쇄로 인해 빌 리루빈이 상승했을 경우에는 내시경적 비담도 배액술이나 경피경간적 담도 배액술을 시행하여 빌리루빈이 $2 \mathrm{mg} / \mathrm{dL}$ 이하로 감소한 후 복합항암요법을 시작하였다. 이전에 다 른 악성 종양이 있던 환자는 제외시켰다. 임상적 이익을 평 가할 수 있는 환자의 기준은 Karnofsky 전신 수행능력이 50
에서 70 사이에 있거나 최소한 두개 이상의 비스테로이드 성 항염증제를 진통제로 복용하는 통증을 가진 환자를 대 상으로 하였다. 임신하였거나 뇌 전이가 있거나 활동성 감 염이 있는 환자는 제외되었다.

\section{2) 치료방법}

Gemcitabine은 체표면적당 $1,000 \mathrm{mg} / \mathrm{m}^{2} / \mathrm{day}$ 를 생리 식염 수 $200 \mathrm{ml}$ 에 혼합하여 1일째, 8 일째, 15 일째 45 분 동안 정맥 주사하였고 28 일 간격으로 반복 투여하였다. UFT-E는 체표 면적 1.75 이상이면 $700 \mathrm{mg} / \mathrm{day}$, 체표면적이 $1.5 \sim 1.75$ 이면 $600 \mathrm{mg} /$ day, 체표면적이 1.5 미만이면 $500 \mathrm{mg} /$ day, 체표면적 이 1.25 미만이면 $400 \mathrm{mg} / \mathrm{day}$ 를 하루에 세 번으로 나누어 8시간마다 경구 투여하였고 Leucovorin은 $45 \mathrm{mg} / \mathrm{day}$ (9정)/ day 고정된 용량으로 하루에 세 번 나누어 역시 8시간 간격 으로 경구 투여하였다. UFT-E와 Leucovorin은 항암치료 1일 부터 21일째까지 지속적으로 투여하였다. 이 복합항암요법 은 28 일 간격으로 반복되었다. 수용 불가능한 독성이 나타 나거나 병이 진행하지 않는 한 최대 6회의 치료를 목표로 하였다.

\section{3) 치료 평가}

치료 시작 전에 전신수행능력과 간기능 및 혈청 생화학 검사와 혈액학적 검사를 시행하였다. CA19-9의 측정과 복 부의 컴퓨터 단층촬영을 시행하였다. 혈액학적 검사 및 혈 청학적 검사는 1 주일 간격으로 시행하였고 CA19-9의 검사 는 매 회의 치료가 끝날 때마다 컴퓨터 단층촬영은 매 2회 의 치료가 끝난 후에 객관적 평가를 위해 촬영하였다. CA19-9 측정은 chemiluninoscent immunoassay (Adviacentaur Bayer, Germany)로 시행하였고 cut-off value는 $37 \mathrm{U} / \mathrm{ml}$ 이었 고 치료 시작 전에 정상보다 높은 환자에서 2 회의 치료가 끝날 때마다 CA19-9을 다시 측정하여 감소되었는지 여부 를 관찰하였다.

치료의 효과를 판정하는 기준은 $\mathrm{WHO}$ 반응 기준을 사용 하였다. 완전관해는 모든 계측가능하고 평가 가능한 병변 이 없어질 때로 정의하였고 부분관해는 계측 가능한 병변 의 최장경과 그 수직의 곱이 $50 \%$ 이상 감소하고 새로운 병 변이 생기지 않을 때로 정의하였다. 진행성 병변은 계측 가 능한 병변의 최장경과 그 수직경의 곱이 $25 \%$ 이상 증가했 거나 새로운 병변이 나타났을 경우로 정의하였고 불변은 완전 관해, 부분 관해, 진행성 병변의 기준에 맞지 않는 모 든 경우로 정의하였다. 완전관해, 부분관해, 불변은 최소한 4 주 이상 지속되었을 경우로 확인하였다. 완전 관해나 부분 관해의 기간은 처음 관해가 확인된 날부터 병이 진행되거 나 재발하거나 어떤 이유로든 사망한 경우로 정하였다. 진 
행까지의 기간은 처음 치료 시작한 날부터 진행성 병변이 발견된 날까지의 기간으로 정하였다. 생존 기간은 처음 치 료 시작한 날부터 사망한 날이나 마지막으로 추적 관찰된 날까지의 기간으로 정하였다. 임상적 이익은 통증과 전신 수행 능력으로 일차적으로 평가하였고 이차적인 평가기준 은 체중 변화로 삼았다. 만일 일차적인 기준 중 최소한 한 가지가 긍정적인 효과이고 다른 한 가지가 악화되지 않는 것이 4주 이상 지속되었을 경우에 임상적 이익이 있다고 평가하였다. 전신수행능력은 Karnofsky 전신수행능력으로 20 이상의 상승이 있을 경우에 긍정적이라고 평가하였다. 통증은 환자의 주관적인 통증의 정도가 visual analogue scale로 $50 \%$ 이상 감소하였거나 진통제의 용량이 $50 \%$ 이하 로 감소되었을 경우에 긍정적으로 평가했다. 만일 전신 수 행 능력과 통증의 일차적인 평가기준이 변화가 없었다면 이차적으로 체중이 치료 시작하기 전보다 $7 \%$ 이상 증가하 였을 경우에 임상적 이익이 있는 것으로 평가했다. 그러나 복수나 부종에 의한 체중 증가는 제외시켰다.

\section{4) 독성과 용량 조절}

독성의 평가는 NCI 독성 기준에 따라 평가하였고, 용량 은 $\mathrm{NCI}$ 독성 3 도 이상일 경우에 조절하였다. 다음 치료가 시작되는 날(이전 치료가 끝난지 29일째)에 절대호중구수 가 $1500 / \mathrm{mm}^{3}$ 미만이거나 혈소판수가 $100,000 / \mathrm{mm}^{3}$ 미만일 경우에는 gemcitabine 투여를 연기시켰고 회복된 후에 100 $\mathrm{mg} / \mathrm{m}^{2}$ 감량된 용량으로 치료를 시작하였다. 8 일째와 15 일 째의 gemcitabine은 절대호중구수 $\leq 1000 / \mathrm{mm}^{3}$ 이거나 혈소판 수 $\leq 75,000 / \mathrm{mm}^{3}$ 인 경우에 투여를 생략하였다. NCI 독성 기 준으로 3 도나 4 도의 혈소판감소증이나 호중구감소증이 있 는 경우에는 UFT-E의 투여를 일시 중지하였고 다음 회의 Gemcitabine의 용량은 $100 \mathrm{mg} / \mathrm{m}^{2}$ 감량시켰다. 또한 NCI 3도 이상의 비혈액학적 독성이 있는 경우에는 UFT-E의 투여를 일시 중지 하였고 독성이 회복된 후에는 $100 \mathrm{mg} / \mathrm{day}$ 씩 감량 시켜서 다시 시작하였다.

\section{5) 통계 분석}

제 2 상 임상 연구의 목표는 진행성 췌장암에서 gemcitabine, UFT-E, Leucovorin복합항암요법의 전체 반응률과 생존기간 및 진행까지의 기간을 구하기 위함이었다. 전체 반응률을 구하고 $95 \%$ 신뢰구간을 구하였다. 생존 기간 및 진행까지 의 기간은 Kaplan-Meier 생존곡선을 통하여 구하였다.

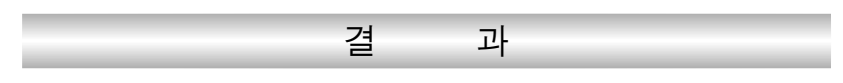

\section{1) 환자 특징}

1999년 3월부터 2000년 3월까지 고려대학교 구로 부속병 원과 안암 부속병원에서 진단된 췌장암 환자 23 명이 이 연 구에 포함되었다. 4 명의 환자가 2 회 이상의 치료를 받지 못 하여 효과의 평가가 불가능하였으나 이 환자들은 독성의 평가에는 포함시켰다. 총 19 명의 환자에서 반응을 평가할 수 있었다. 효과 평가가 불가능했던 4 명의 환자 중 2 명은 독성과 관련된 환자의 거절이 원인이었고 2 명은 추적관찰 을 할 수 없었던 환자이다. 평가 가능했던 환자들의 특징은 Table 1 과 같다. 이전에 항암 치료를 받거나 방사선 치료를 받은 환자는 없었고 수술 후 재발한 환자 2 명이 포함되었 다. 환자 중에서 치료 시작 전에 폐쇄성 황달이 있어서 내시 경적 비담도 배액술이나 경피경간적 담도배액술이 필요했 던 환자는 다섯 명이었다. 이 환자들은 배액술을 시행한 후 총 빌리루빈이 $2 \mathrm{mg} / \mathrm{dl}$ 미만으로 감소 후 복합항암요법을 시작하였다.

Table 1. Patient characteristics

\begin{tabular}{|c|c|c|c|}
\hline \multirow{2}{*}{ Characteristics } & \multicolumn{3}{|c|}{ Intent-to-treat patients } \\
\hline & Number & & $\%$ \\
\hline Enrolled patients & & 23 & \\
\hline Evaluable patients & & 19 & \\
\hline Age & & 58 & \\
\hline Range & & $42 \sim 70$ & \\
\hline \multicolumn{4}{|l|}{ Sex } \\
\hline Male & 12 & & 52.2 \\
\hline Female & 11 & & 47.8 \\
\hline \multicolumn{4}{|l|}{ *ECOG PS } \\
\hline 0 & 0 & & 0 \\
\hline 1 & 14 & & 60.8 \\
\hline 2 & 9 & & 39.2 \\
\hline \multicolumn{4}{|l|}{ Stage } \\
\hline Locally advaned & 11 & & 47.8 \\
\hline Metastatic & 12 & & 52.2 \\
\hline \multicolumn{4}{|l|}{ Metastasis site } \\
\hline Liver & 8 & & 34.8 \\
\hline Lymph node & 11 & & 47.8 \\
\hline Lung & 1 & & 4.3 \\
\hline Adrenal & 1 & & 4.3 \\
\hline Bone & 2 & & 8.7 \\
\hline
\end{tabular}

*ECOG PS: Eastern cooperative oncology group performance status 


\section{2) 치료 요약}

총 82회의 복합항암요법이 시행되었다. 항암요법 치료 횟수의 중앙값은 4 회(범위: $1 \sim 8$ 회)이었다. 4 명의 환자가 첫 회의 치료만 마치고 다음 치료를 하지 못하였다. 2 명은 독 성과 관련된 환자의 거절이 원인이고 2 명은 추적 관찰을 할 수 없었던 환자이다. 이 4명의 환자들은 치료 후 복부 컴퓨터 단층 촬영을 시행할 수 없었으므로 반응을 평가할 수 없었다. 4 명의 환자는 2 회의 치료 후에 병의 진행으로 치료를 중단하였다. Gemcitabine의 생략이 필요했던 환자는 3 명 $(13 \%, 7$ 회/82회)이었고 UFT-E의 용량을 줄이거나 일시 적으로 중단하는 것이 필요했던 환자는 4 명(17.4\%)으로 대 부분의 환자에서 계획된 용량대로 치료되었다.

\section{3) 반응과 생존기간}

완전 관해는 한 명도 없었고 부분 관해가 3 명으로 전체 반응률은 $15.3 \%$ 이었다. 12 명 $(57.9 \%)$ 의 환자가 불변이었 고 4 명 $(26.3 \%)$ 가 2 회의 치료 후에 진행하였다. 환자의 반 응률과 진행까지의 기간 및 생존 기간에 관한 결과는 Table 2와 같다. 전체 반응률은 낮았으나 진행까지의 기간 을 살펴 보면 불변인 환자에서도 6개월 이상인 경우가 전 체 불변환자의 $50 \%$ 에서 관찰되고 그 중앙값은 8 개월에 달했고 생존 기간의 중앙값은 8 개월이었으며 1 년 생존율 은 $22 \%$ 에 달하였다. Kaplan-Meier 생존 곡선의 결과는 Fig. 1과 같다.

Table 2. Overall response rate and *TTP and survival duration of Gemcitabine, UFT-E, Leucovorin combination chemotherapy in advanced pancreatic cancer

\begin{tabular}{lccc}
\hline Response & Number & $\%$ & *TTP (months) \\
\hline${ }^{\dagger} \mathrm{CR}$ & 0 & 0 & \\
${ }^{\ddagger} \mathrm{PR}$ & 3 & 15.8 & $4.5+, 8.3,12$ \\
${ }^{\S} \mathrm{SD}$ & 12 & 57.9 & $3,3,3,4,6,6,7+$, \\
${ }^{\|} \mathrm{PD}$ & 4 & 26.3 & \\
Overall response & 3 & 15.8 & \\
${ }^{*} \mathrm{TTP}$ (months) & & & \\
Median & 8 & & \\
Range & $3 \sim 12$ & \\
Survival duration & & \\
Median & 8 & \\
Range & $1.5 \sim 13+$ \\
1 year survival & $22 \%$ & \\
\hline
\end{tabular}

*Time to progression, ${ }^{\dagger}$ Complete response, ${ }^{\ddagger}$ Partial remission, ${ }^{\S}$ Stable disease, "Progressive disease

\section{4) 임상적 이익 평가}

전신수행 능력과 통증, 체중 변화 등으로 평가한 임상적 이익에서는 평가 가능했던 19명의 환자에서 11 명(57.9\%) 에서 긍정적인 임상적 이익을 보였다. 11 명 중 3 명은 Karnofsky 전신수행능력이 20 이상 상승함과 동시에 통증 이 $50 \%$ 이상 감소했던 환자이고 5 명은 통증에는 변화 없이 Karnofsky 전신수행능력이 20 이상 상승했던 환자였으며 2 명은 전신 수행능력에 변화 없이 통증이 $50 \%$ 이상 감소했 던 환자였다. 전신수행능력이나 통증의 1 차적인 측정에는 변화 없이 치료 시작전보다 체중이 $7 \%$ 이상 상승했던 환자 는 1 명이었다. 치료 시작전에 통증이 있었던 11 명 중 5 명이 $50 \%$ 이상 통증이 감소하였고 Karnofsky 전신수행능력이 20 이상 상승한 환자는 8 명이었다.

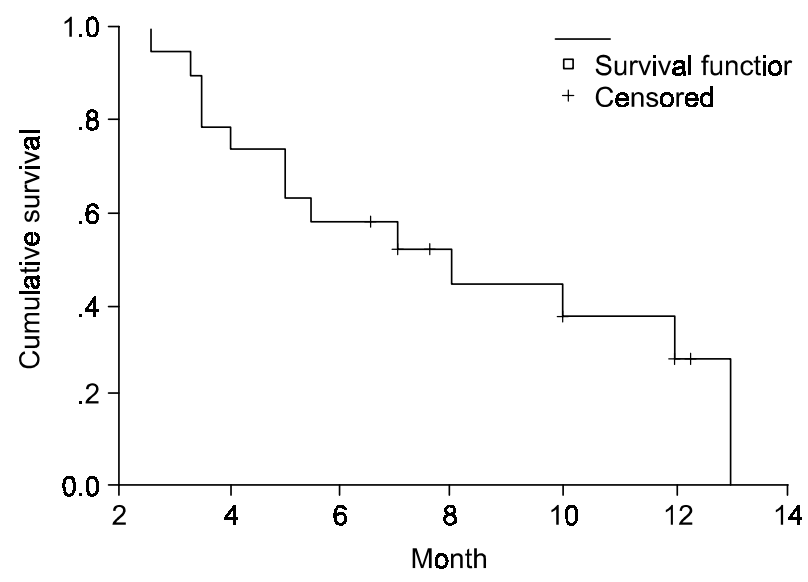

Fig. 1. Overall survival of gemcitabine, UFT-E, leucovorin combination chemotherapy in advanced pancreatic cancer

Table 3. Toxicity of gemcitabine, UFT-E, leucovorin combination chemotherapy in advanced pancreatic cancer

\begin{tabular}{llc}
\hline \multirow{2}{*}{ Toxicity } & Grade 3 & Grade 4 \\
\cline { 2 - 3 } & 환자 수(\%) & 환자 수(\%) \\
\hline *Neutropenia & $4(17.4)$ & $3(13.0)$ \\
Thrombocytopenia & $1(4.3)$ & \\
Nausea/vomiting & $2(4.3)$ & \\
Stomatitis & $1(4.3)$ & \\
Diarrhea & $1(4.3)$ & \\
\hline
\end{tabular}

Toxicity criteria: modified NCI grade, *There are two neutropenic fever among four neutropenia but no treatment related death 


\section{5) CA19-9 감소와 생존기간}

CA19-9이 치료 시작 전에 높았던 환자는 전체 23명의 환 자 중에서 18 명이었고 2 회의 치료가 끝난 후에 CA19-9이 $20 \%$ 이상 감소했던 환자는 11 명으로 $61.1 \%$ 에서 감소하였 고 이 중 9명은 $50 \%$ 이상 현저하게 감소하였다. CA19-9의 감소가 있었던 환자 11 명 중 8 명이 임상적 이익이 있었고 CA19-9의 감소가 없었던 환자 8명 중 임상적 이익이 있었 던 환자는 1 명이었다 $(72.7 \%$ vs $12.5 \%, \mathrm{p}=0.005)$. CA19-9의 감소가 있는 환자와 없는 환자의 생존 기간의 중앙값은 10 개월과 4 개월로 차이가 있었으나 $\mathrm{p}=0.25$ 로 통계적 의미는 없었다.

\section{6) 독성}

23 명의 환자에서 독성을 평가하였다. 가장 흔한 독성은 호중구 감소증이었다(Table 3). 3 도 이상의 호중구 감소증은 7명으로 $30.4 \%$ 에서 있었으나 호중구 감소성 발열이나 호중 구 감소와 관련된 감염은 없었다. 그 외 비혈액학적 독성으 로는 오심, 구토가 흔하였으나 3 도 이상의 오심, 구토는 2 명 에 불과하였고 그 외 3 도 이상의 설사, 점막염은 각각 한 명에서 관찰되었다. 대개 호중구감소증이나 오심, 구토, 설 사, 점막염 등은 경구 UFT-E를 일시적으로 끊으면 회복되 었다. 호중구 감소성 발열은 2 명에서 관찰되었으나 치료와 관련된 사망은 한 명도 없었다.

\section{고 찰}

최근까지도 췌장암은 항암치료에 잘 반응하지 않는 것으 로 알려져 있어 항암치료를 하는 것이 진행성 췌장암에 별 도움이 되지 않는다고 생각되었다. 사실상 대부분의 항암 제들이 진행성 췌장암에 $15 \%$ 미만의 실망스러운 반응률을 보였고 생존 기간의 연장이나 삶의 질 향상에서도 미미한 실정이었다. 그러나 최근에 진행성 췌장암에서 항암치료가 생존을 늘리고 증상 완화 및 삶의 질 향상에 효과적이라는 몇몇 3상 임상 연구들의 보고가 있었다. 그러나 그 반응 기 간은 매우 짧았다. 전신수행능력이 나쁜 환자를 제외시킨 연구에서도 생존 기간의 중앙값은 $2.5 \sim 6$ 개월 이내였다. 더 구나 복합항암요법이 단독 치료보다 더 좋은 효과를 나타 내는지도 3상 연구에서 증명된 바 없다(3 6).

이번 연구에서는 진행성 췌장암에서 생존율의 향상 및 증상 완화와 삶의 질 향상에 효과를 보인 gemcitabine과 지 난 수십년간 췌장암에서 가장 보편적으로 사용하였던 5-FU 의 경구제제인 UFT-E와 Leucovorin의 복합항암요법으로 반 응률은 $15.8 \%$ 에 불과하였으나 생존 기간의 중앙값이 기존
의 다른 항암 요법에 비해 열등하지 않았고 진행까지의 기 간이 8 개월에 이르고 $57.9 \%$ 에서 임상적인 이익이 있었다. 췌장암의 반응률은 측정 가능한 병변이 종양 자체에 의한 것인지 염증이나 섬유화에 의한 것인지 감별이 어렵기 때 문에 컴퓨터 단층 촬영 및 방사선학적 검사에 의한 반응 평가가 객관적이기 어렵다는 단점이 있으므로 반응률 자체 보다는 생존기간, 진행까지의 기간 및 임상적 이익의 여부 로 평가함이 더 합당할 것으로 생각되는 경향이다. 따라서 본 연구에서 반응률이 낮음에도 불구하고 불변의 반응을 가졌던 환자들이 진행까지의 기간이 길고 생존기간의 연장 을 보인 것은 의미 있다고 할 수 있다. 이는 최근 Reni등이 보고한 생존 기간의 중앙값인 10 개월에는 못 미치는 결과 였지만 이들의 연구는 전신수행능력이 비교적 좋고 적극적 으로 방사선 치료 및 수술까지 시행했기 때문으로 생각된 다(21). 국내 연구 중에서는 1991년에 이 등의 5-FU, epirubicin, cisplatin 및 5-FU, cisplatin 복합항암요법의 생존 기간 의 중앙값이 각각 7 개월, 6 개월이었던 것에 비해 우월한 결 과를 보였다(22).

이번 연구에서는 CA19-9 값을 함께 측정하고 이것의 임 상적 의의를 함께 보았는데 $61.1 \%$ 에서 $20 \%$ 이상 항암 치료 시작 전 보다 감소되는 소견을 보였고 감소된 환자의 대부 분(9/11, 82\%)이 $50 \%$ 이상 대폭 감소하였다. 이번 연구에서 는 CA19-9 감소된 환자군과 감소되지 않은 환자군에서 생 존 기간의 차이가 있었으나(10개월 대 4개월, $\mathrm{p}=0.25$ ) 통계 적인 의미는 없었다. 그러나 일련의 연구들에서 CA19-9의 감소여부가 항암 치료 후 예후 및 생존 기간에 영향을 미친 다는 것이 보고되었고 $(23,24)$ 이번 연구에서 통계적인 의미 가 없었던 것은 대상 환자의 수가 적었기 때문으로 생각된 다. 현재 방사선학적 검사는 췌장암의 병변을 객관적으로 평가한다는 장점은 있으나 염증과 섬유화 등을 감별하지 못하는 단점이 있고 임상적 이익 및 삶의 질 평가는 환자나 임상가의 주관적 의견이 개입되기 쉬운 단점이 있으므로 CA19-9의 측정과 감소여부가 비록 단독으로 반응을 평가 하는 데는 무리가 있지만 임상적 이익 및 방사선학적 검사 와 함께 반응 평가에 도움이 되리라 생각되고 추후 더 많은 환자 수를 대상으로 연구해볼 가치가 있을 것이다.

진행성 췌장암에서 gemcitabine, UFT-E, leucovorin 복합항 암 요법은 독성면에서도 3 도 이상의 호중구감소증이 $30.4 \%$ 이고 오심, 구토 및 점막염, 설사 등의 비혈액학적 독성도 미미하였다. 더구나 독성이 나타났을 경우 UFT-E를 일시적 으로 끊음으로써 쉽게 독성을 조절할 수 있었다. 최근 5-FU 의 지속정주와 gemcitabine의 복합항암요법이 좋은 반응률 을 보고한바 있으나(21) 이는 중심정맥관을 삽입하고 환자 가 계속 입원하여 치료를 받아야 하기 때문에 비용문제 및 
중심정맥관 삽입에 따른 합병증이 문제가 되고 삶의 질 저 하를 유발시키는 단점이 있다. 그러나 Gemcitabine, UFT-E, Leucovorin 복합항암 요법은 외래에서 시행할 수 있고 환자 의 삶의 질 향상에도 도움이 될 것으로 생각된다.

따라서 Gemcitabine, UFT-E, Leucovorin 복합 항암 요법은 앞으로 진행성 췌장암 환자에서 좀 더 환자수를 늘려서 연 구하고 그 독성이 적으므로 다른 항암제와의 복합 항암요 법에 대해서도 연구해볼 가치가 있을 것이다.

\section{결 론}

진행성 췌장암에서 Gemcitabine, UFT-E, Leucovorin 복합 항암요법은 반응률은 낮지만 생존기간의 연장 및 임상적 이익이 있고 그 독성은 수용 가능한 것이었다.

\section{REFERENCES}

1. Niederhuber J, Brennan MF, Menck HR. The national cancer database on pancreatic cancer. Cancer 1995;76:1671-1677.

2. Kelly DM, Benjamin IS. Pancreatic carcinoma. Ann Oncol 1995;6:19-28.

3. Moore M. Activity of gemcitabine in patients with advanced pancreatic carcinoma. A review. Cancer 1996;78:633-638.

4. Topham C, Glees J, Rawson NSB, Woods EM, Coombes RC. Randomised trial of epirubicin alone versus 5-fluorouracil, epirubicin and mitomycin $\mathrm{C}$ in locally advanced and metastatic carcinoma of the pancreas. Br J Cancer 1991;64:179-181.

5. Topham C, Glees J, Coombs RC. Comparison of single agent epirubicin and 5-FU/epirubicin/mitomycin in patients with advanced adenocarcinoma of the pancreas. Oncology 1993;50: 78-83.

6. Bukowski RM, Fleming TR, Macdonald JS. Evaluation of combination chemotherapy and phase II agents in pancreatic adenocarcinoma. Cancer 1993;7:322-325.

7. Casper ES, Green MR, Kelsen DF, Heelan RT, Brown TD, Flombaum CD, Trochanowski B, Tarassoff PG. Phase II trial of gemcitabine in patients with adenocarcinoma of the pancreas. Invest New Drugs 1994;12:29-34.

8. Burris HA III, Moore MJ, Andersen J, Green MR, Rothenberg ML, Modiano MR, Cripps MC, Portenoy RK, Storniolo AM, Tarassoff P, Nelson R, Dorr FA, Stephens CD, Von Hoff DD. Improvement in survival and clinical benefit with gemcitabine as first-line therapy for patients with advanced pancreas cancer: A randomized trial. J Clin Oncol 1997;15:2403-2413.

9. Rothemberg ML, Moore MJ, Cripps MC, Andersen JS, Portenoy RK, Burris HA $3^{\text {rd }}$, Green MR, Tarassoff PG, Brown TD, Casper ES, Storniolo AM, Von Hoff DD. A phase II trial of gemcitabine in patients with 5-FU-refractory pancreas cancer. Ann Oncol 1996;7:347-353.

10. Carmichael J, Fink U, Russell RCG, Spittle MF, Harris AL, Spiessi G, Blatter J. Phase II study of gemcitabine in patients with advanced pancreatic cancer. Br J Cancer 1996;73:101105.
11. Moore MJ, Andersen J, Burris HA III. A randomized trial of gemcitabine versus 5-FU as first line therapy in advanced pancreatic carcinoma. Proc Am Soc Clin Oncol 1995;14:199, 1995 (abstr 473)

12. Lokich JJ, Ahlgren JD, Cantrell J, Heim WJ, Wampler GL, Gullo JJ, Fryer JG, Alt DE. A prospective randomized comparison of protracted infusional 5-fluorouracil with or without weekly bolus cisplatin in metastatic colorectal carcinoma: A Mid-Atlantic Oncology Program study. Cancer 1991; 67:14-19.

13. Lokich JJ, Ahlgren JD, Cantrell J, Heim WJ, Wampler GL, Gullo JJ, Fryer JG, Alt DE. A prospective randomized comparison of protracted infusional 5-fluorouracil with or without weekly bolus cisplatin in metastatic colorectal carcinoma: A Mid-Atlantic Oncology Program study. Cancer 1991;67:14-19.

14. Bertheault-Cvitkovic F, Levi F, Soussan S, et al. Circadian rhythm-modulated chemotherapy with high-dose 5-fluorouracil: A pilot study in patients with pancreatic adenocarcinoma. Eur $\mathbf{J}$ Cancer 1993;29A:1851-1854.

15. Rothman H, Cantrell JE, Lokich J, et al. Continuous infusion 5-fluorouracil plus weekly cisplatin for pancreatic adenocarcinoma. A Mid-Atlantic Oncology Program study. Cancer 1991;68:264-268.

16. Nicolson M, Webb A, Cunningham D, Norman A, O'Brien M, Hill A, Hickish T. Cisplatin and protracted venous infusion 5-fluorouracil (CF): Good symptom relief with low toxicity in advanced pancreatic carcinoma. Ann Oncol 1995;6:801-804.

17. Evans TRJ, Lofts FJ, Mensi JL, Glees JP, Dalgleish AG, Knight MJ. A phase II study of continuous infusion 5fluorouracil with cisplatin and epirubicin in inoperable pancreatic cancer. Br J Cancer 1996;73:1260-1264.

18. Kim YH, Shin SW, Kim BS, Park YT, Kim JG, Kim JS. A phase II trial. Oral UFT and leucovorin in patients with advanced gastric carcinoma. Oncology (Huntingt) 1997;11 (Suppl.10):119-123.

19. Jeen YT, Yoon SY, Shin SW, Kim BS, Mok YJ, Kim CS, Hyun JH, Kim JS, Kim YH. Phase II trial of epirubicin, cisplatin, oral uracil and tegafur, and leucovorin in patients with advanced gastric carcinoma. Cancer 2001;91(12):22882293.

20. Heinemann V, Xu YZ, Chubb S, SenA, Hertel LW, Grindey GB, Plunkett W. Inhibition of ribonucleotide reductasse in CCRF-CEM cels by 2',2'difuluorodeoxycytidine. Mol Pharmacol 1991;38:561-572.

21. M. Reni, P. Passoni, M. G. Panucci, R. Nicoletti, L. Galli, G. Balzano, A. Zerbi, V. Di Carlo, E. Villa. Definitive results of a phase II trial of cisplatin, epirubicin, continuous-infusion fluorouracil, and gemcitabine in stage IV pancreatic adenocarcinoma. J Clin Oncol 2001;19:2679-2686.

22. Lee KH, Kang WK, Suh CI, Park YS, Kim HT, Kang KK, Ki HJ, Heo DS, Bang YJ, Yoon YB, Kim NK. 5-Fluorouracil, Epirubicin, Cisplatin (FEP) and 5-Fluorouracil, Cisplatin (FP) combination chemotherapy for advanced pancreatic carcinoma. J Korean Cancer Assoc 1991;23(2):315-322.

23. Halm H, Schumann T, Schiefke I, Witzigmann H, Mossner J, Keim V. Decrease of CA19-9 during chemotherapy with gemcitabine predicts survival time in patients with advanced pancreatic cancer. Br J Cancer 2000;82(5):1013-1016.

24. Gogas H, Lofts FJ, Evans TRJ, Daryanani S, Mansi JL. Are serial measurements of CA19-9 useful in predicting response to chemotherapy in patients with inoperable adenocarcinoma of the pancreas? $\mathrm{Br} \mathrm{J}$ Cancer 1998;77:325-328. 